\title{
Kakugi Ko, Kalambuan Mo (KKK Mo) as an Extension Program for Daycare Workers: An Impact Study
}

\author{
Maria Nancy Q. Cadosales ${ }^{1}$, Angelito Jr. B. Cabanilla², and Naila Y. Beltran ${ }^{3}$ \\ ${ }^{1}$ Cebu Normal University, https://orcid.org/0000-0003-1140-920X \\ ${ }^{2}$ Cebu Normal University, https://orcid.org/0000-0002-8986-474X \\ ${ }^{3}$ Cebu Normal University, https://orcid.org/0000-0003-4295-5182 \\ 1 Email Correspondence: cadosalesm@cnu.edu.ph
}

\section{Abstract}

The Commission on Higher Education emphasized that extension programs provide the space to discover practical evidence, and science-based answers to real-world social, economic, and environmental challenges for partner communities. This descriptive study looked into the impact of an extension program to address the needs of the day care workers. It employed a questionnaire, unstructured interview, and focus group discussion in gathering the data. The study revealed that the parents and the social workers were responsive to the needs of the day care workers. Seven themes emerged namely: eliciting parents and children's active involvement, improving collaboration and communication, learning from seminars, availing necessities and learning resources, improving pedagogical competence and practices of DCWs, and improving the learning environment. The extension program helped the day care workers established sustainable and effective day care centers through forging and sustaining strong partnerships with parents, government, and nongovernment organizations.

Keywords: day care workers, day care centers, Theory of Change, impact study, Philippines

\subsection{Introduction}

Education is a concern of all. It is one of the many priorities of the United Nations Educational, Scientific and Cultural Organization (UNESCO, 2015) as stated in the Sustainable Development Goals (SDG) that ensures comprehensive and impartial quality instruction and advances long-lasting learning of students. Agencies are mandated to take care of the education sector from preschool to higher education.
Early childhood education plays a crucial job in developing children and provides valuable assistance to their families. The impact of the quality of childcare is significant for the holistic development of children (Peisner-Feinberg, 2007). Moreover, Fuqua and Greenman (1982) said that day care education potentially impacts children's growth.

Child care in the Philippines is managed by the Department of Social Welfare and Development 
(DSWD) where it prioritizes the development of children's well-being and recognizes the significant role of Day Care Service (DSC) as a response to the Philippines' ratification of the Convention on the Rights of the Child (CRC) on July 26, 1990.

The day care center (DCC) is managed by a volunteer day care worker (DCW) who handles the children. In 2004, the DSWD sets standards for DCC through Administrative Order (AO) no. 29 and Early Childhood Care and Development (ECCD) Act of 2000 or Republic Act 8980 . Further, AO no. 29 sets a new guideline on the age requirement of entrant day care children from ages zero (0) to 5.11 years old and three (3) years old to 4.11 years old. DSWD's new rule guarantees to address the children's physical, intellectual, social, and emotional needs. Day Care workers perform undertakings similar to the duty of parents, such as providing supervision and teaching life skills to the children (Bastiaanssen et al., 2012). They assess, evaluate, and set goals for the children in cooperation with the family and the community.

"Kakugi Ko, Kalambuan Mo" supports the fourth goal of Sustainable Development Goals (SDG) in providing quality education to children. The program also endorses the 17th SDG to achieve goals in partnership. Moreover, KKK Mo upholds the mission of the University, which is to be a resource in enhancing the quality of life among Cebuanos by empowering the DCWs in nurturing the well-being of the children.

One of the tasks of DCWs involves teaching children aged three to 4.11 who are in the third stage of psychosocial development of Erikson (1963 in Woolfolk, 2016). This is the stage of initiative versus guilt where kids start to declare their capacity and authority over the world by coordinating a play and other social collaboration. Piaget (1936 in Woolfolk, 2016) emphasized that children between two to seven years old begin to engage in symbolic play and learn to manipulate symbols. Both Erikson (1963 in Woolfolk, 2016) and Piaget (1936 in Woolfolk, 2016) stressed the importance of guided play and the use of manipulatives in teaching early childhood. Thus, DCWs need to design appropriate activities for children to develop their cognitive and socio-emotional skills. Thus, the KKK Mo extension program designed enhancement activities for the DCWs to help them plan their activities suited to the level of the Day Care children.

In addition to the many things that the day care workers need to address is the accreditation of the DCC. AO No. 29 further states that the DSWD has the authority to accredit day care centers and day care workers. The legal bases of the DCCs accreditation are PD No. 603 (1974), RA No. 6972 (1990), RA No. 7160 (1991), EO No. 340 (1997), EO No. 221 (2003), RA No. 8980 (2000), and EO No. 685 (2008). Compliance with accreditation requirements grants DCCs and DCWs to operate for three to five years. Accredited DCCs and DCWs receive an additional honorarium of $\mathrm{Php}$ 500 per month. The extensionists aligned their enhancement activities to prepare the DCCs, train the DCWs and provide seminars to parents, and help DCCs comply with the requirements for the accreditation of the day care centers.

In Illinois, Scriven and Baldridge (1982) proposed an in-service training program for day care workers in the areas of child growth and development, working with children with special needs, developing classroom activities, planning for a total program, and working with parents. While, Løvgren (2016) examined the emotional exhaustion in day care workers in the three aspects of pedagogical work such as clear roles, clear expectations, and co-worker support.

In the Philippine setting, studies in early childhood are few. Escarlos, Bermillo, Magday, and Salon (2019) investigated the impact of mentoring 
barangay day care workers and found that the extension program improved the instructional services of day care workers. Del Rosario et al. (2018) enumerated few studies about DCCs and DCWs, including Abulon's (2013) barangay day care center status survey in the country where results showed that the emergence of the day care centers in the country proved the states' deepening commitment to uphold early childhood education. Cadosales' (2011) analysis of DCWs' teaching needs such as teaching reading, teaching number concepts, teaching strategies, production of instructional materials and pedagogy and Reyes' (1996) study of variables affecting day care policy implementation in one of the Philippine regions found that critical variables (such as output, environment, organization, process) and constraints (like financial constraints in the implementation of the basics of the day care law, lack of concern on the part of the local government units (LGUs) for the pursuit of a genuine day care service program mismatch the LGU's capacity to satisfy the demands of the day care law in the framework of the system. Among the previous studies, only Escarlos et al. (2019) mentioned an impact study conducted about day care workers. In this light, the present study aimed to describe the impact of the KKK Mo extension program on DCWs.

An impact study identifies the benefits that a program brings to the beneficiaries. The impact study on the KKK Mo extension program employed the Theory of Change. Serrat (2017) said that the Theory of Change is an action model such as a policy, plan, program, or project that leads to the intended outcome through a sequence of outcomes. Change is a result of the assessment (Pines \& Maslach, 1980) as conducted by extensionists with the DCWs. Furthermore, Harries et al. (2014) mentioned that the Theory of Change is a tool to help the extensionists describe the concerns they are trying to address, the changes they want to make (outcomes), and the plans they want to do (activities). By the end of the change process, the extensionists gain a clear idea of what the project achieved based on strategies used.

The logic model described the Theory of Change in establishing excellent training ground for volunteer DCWs, with the help of the parents and the community to constitute an active day care center. The logic model allowed for a more detailed, particularly about how a project is delivered. It started with a final goal and worked backward to the intermediate outcomes. The logic model revealed the beneficiaries' knowledge and skills, attitudes and thinking, and behaviors toward attaining the final goal (Harries et al., 2014).

The KKK Mo extension program identified the needs of the DCCs and DCWs. The extensionists provided a series of activities to achieve the program outcome which is establishing an excellent training ground for the day care workers. The DCWs are volunteers who received a monthly honorarium of Php 3,000 from DSWD and Php 1,000 from the municipality. These DCWs earned some units in tertiary education but did not finish Early Childhood Education. As volunteers in the DCCs, they need to learn the psychology of teaching children, strategies in teaching, appropriate learning materials for toddlers, classroom structuring, and collaborating with families and communities.

The issues and concerns enumerated in the preparation of the day care centers and day care workers for accreditation motivated the faculty members in a State University to extend assistance to DCWs. The community extension program hoped to prepare the day care center to be a better 
place conducive to learning, to help the DCWs learn better ways in teaching and managing the day care children, and to assist them in complying with accreditation requirements of DSWD. To address these needs, the extension program on "Kakugi Ko, Kalambuan Mo" (KKK Mo) was implemented from the mid-year of 2017 to the present.

\section{Objective of the Study}

The study described the impact of the KKK Mo extension program to assist the volunteer day care workers in establishing sustainable and effective day care centers. Specifically, this paper described the DCWs experiences with various stakeholders and the participants' encounters with the KKK Mo extension program.

\subsection{Methodology}

The study utilized mixed methods designs. For the quantitative aspect, a descriptive survey design was used. For the qualitative aspect, a phenomenological approach utilizing unstructured interviews and focus group discussions were employed. The participants were three day care workers, ten barangay officials, 30 parents, and 15 volunteers of the Buddhist Compassion Relief Tzu Chi Foundation, the partner non-government organization (NGO) in a barangay in Northern Cebu, Philippines. The study used purposive sampling. Participants who were actively involved in the activities initiated by the KKK Mo extension program were included in the study.

The indicators in the researcher-made questionnaire were formulated based on the roles and responsibilities of the day care workers in managing the day care centers in collaboration with various stakeholders. The questionnaire was validated by experts in community extension programs. It used a four-point Likert scale with 1 as not responsive, 2 as moderately responsive, 3 as responsive, and 4 as highly responsive. The day care workers answered the survey questionnaire.

The qualitative method described the experience of the day care workers, parents, barangay officials, and the partner nongovernmental organization about the Kakugi Ko, Kalambuan Mo (KKK Mo) extension program. These data were generated from the unstructured interviews and focus group discussions (FGD) done by one of the researchers. The unstructured interviews were done separately on scheduled visits while the FGD was done after the year-end get together as a way to evaluate the extension program. The grand tour questions asked during the unstructured interview and FGD were "What is your experience with the KKKMo extension program? What is the impact of KKK Mo extension program to you as a day care worker, parent, barangay official, or volunteer?" The follow-up probing questions were asked to derive a thorough description of the participants' experience with the KKK Mo extension program. A recorder was used during the interview to assure the accuracy and completeness of the participants' responses.

The qualitative responses of the participants were analyzed following the seven steps of the thematic approach of Colaizzi (1978) such as reading and re-reading the proceedings of the unstructured interview and FGD, extracting significant statements, formulating meanings, organizing the collection of meanings into a cluster of themes, integrating the cluster of themes into an exhaustive description, establishing the fundamental structure of the identified phenomenon, and returning to participants for validation of the identified themes/phenomena. The thematic analysis was done based on the interview transcripts with parents, barangay 
kagawad, barangay chairman, and the minutes of the focus group discussion (FGD) with the DCWs, officers, and volunteers of the Buddhist Compassion Relief Tzu Chi Foundation, and the proponents of the KKK Mo program.

The informed consent was sought from the DCWs, parents, barangay officials, and volunteers from Buddhist Compassion Relief Tzu Chi Foundation to ensure the ethical considerations of the study. Their identities were not revealed in any part of the research report to ensure anonymity and confidentiality.

\section{Research Paradigm}

The Theory of Change was also employed in the study to describe the impact of the KKK Mo extension program. To establish a sustainable and effective day care center, the needs of the day care workers were assessed. These workers were provided with regular enhancement activities to help them manage the day care center and supported by the barangay officials representing the local government unit, the partner nongovernment organization, parents, and community as shown in Figure 1.

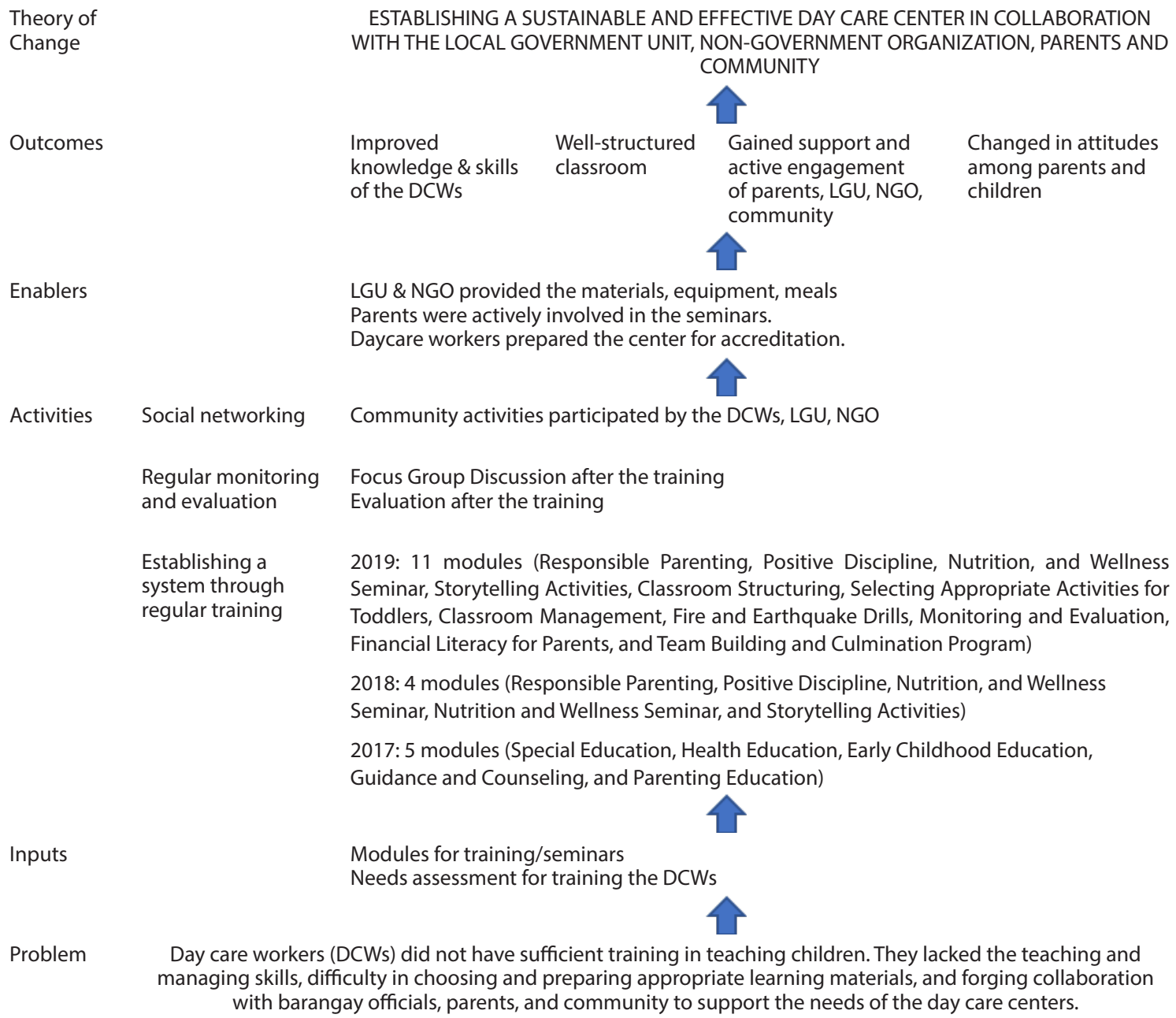

Gained support and active engagement of parents, LGU, NGO, community

Enablers

Activities Social networking

Regular monitoring and evaluation

Establishing a system through regular training

LGU \& NGO provided the materials, equipment, meals Parents were actively involved in the seminars. Daycare workers prepared the center for accreditation.

Community activities participated by the DCWs, LGU, NGO

Focus Group Discussion after the training

Evaluation after the training

2019: 11 modules (Responsible Parenting, Positive Discipline, Nutrition, and Wellness Seminar, Storytelling Activities, Classroom Structuring, Selecting Appropriate Activities for Toddlers, Classroom Management, Fire and Earthquake Drills, Monitoring and Evaluation, Financial Literacy for Parents, and Team Building and Culmination Program)

2018: 4 modules (Responsible Parenting, Positive Discipline, Nutrition, and Wellness Seminar, Nutrition and Wellness Seminar, and Storytelling Activities)

2017: 5 modules (Special Education, Health Education, Early Childhood Education, Guidance and Counseling, and Parenting Education)

Modules for training/seminars Needs assessment for training the DCWs with barangay officials, parents, and community to support the needs of the day care centers. 


\subsection{Results and Discussion}

The results of the study were presented according to the day care workers' experiences with various stakeholders and the participants' encounters with the KKK Mo extension program as described in the emerging themes.
Day Care Workers' Experiences with Stakeholders

The barangay officials, officers, and volunteers of the partner $\mathrm{NGO}$ and parents constitute the stakeholders. The extensionists used a questionnaire to describe the experiences of the DCWs with the stakeholders as shown in Table 1.

Table 1. Day care workers' experiences with various stakeholders

\begin{tabular}{l} 
Statement \\
\hline $\begin{array}{l}\text { The parents participate in parent education on } \\
\text { different topics or issues, i.e., alternative discipline, } \\
\text { responsible parenthood. }\end{array}$
\end{tabular}

2. The parents assist in the complementary feeding program for the children at the center.

3. The parents contribute to the preparation of an annual action plan in support of the Day Care Service.

4. The parents support the implementation of one or more planned projects.

5. The LGU and community leaders allocate an adequate budget for the DCCs.

6. The LGU and community leaders ensure the timely procurement of needed materials.

7. The LGU and community leaders ensure continuity of service of DCWs regardless of political affiliation.

8. The LGU and community leaders manifest ownership and accountability for the DCCs.

9. The social worker or ECCD Focal Person follows up on program implementation and provides technical assistance to the DCWs regularly.

10. The social worker or ECCD Focal Person conducts session observations and conferences for peer support and exchange with the DCWs.

11. The social worker or ECCD Focal Person facilitates the training and development of the DCWs based on the workers' needs.

12. The social worker or ECCD Focal Person collaborates with the DCWs in planning the highly responsive curriculum.

\section{Mean Qualitative Description}

3.5 Highly Responsive

4.0 Highly Responsive

3.5 Highly Responsive

4.0 Highly Responsive

3.5 Highly Responsive

3.5 Highly Responsive

3.5 Highly Responsive

3.5 Highly Responsive

4.0 Highly Responsive

4.0 Highly Responsive

4.0 Highly Responsive

3.5 Highly Responsive 
The day care workers have a good relationship with the parents in terms of assistance in the feeding program and implementation of one or more projects. However, there is a need to strengthen the DCWs and the parents' collaboration in the areas of parents' education on different topics or issues, and parents' participation in the preparation of the annual action plan in support of the Day Care Service. Before the KKK Mo extension program was implemented, the DCWs had encountered difficulty inviting resource speakers for parents' education in formulating the annual action plan. These needs of the DCWs and parents were addressed through the seminars which enabled them to craft their annual action plan as an output. The DCWs appreciated the involvement of the parents in the activities of the center. Garcia and Thornton's (2014) mentioned that family participation in learning leads to improving student performance, decreasing absenteeism, and restoring faith in their children's education. Moreover, Lau et al. (2011) stated that parental involvement is associated with a broad scope of positive child outcomes such as excellent academic performance, healthy behavior, and social skills. Finally, Ntekane (2018) concluded that parental involvement in education served as the glue that helped make learning fun for children and inspired them to perform better.

The social worker assigned to monitor the DCCs and who also represented the local government unit was very responsive to the needs of the DCWs in terms of program implementation and provided technical assistance, conducted session observations and conferences, and training facilitation. However, the DCWs felt that the social worker needs to strengthen collaboration in planning the curriculum. The KKK Mo extensionists addressed this concern by providing seminars on making lesson guides, planning for instruction, choosing developmentally appropriate learning activities for day care children, using instructional materials, and structuring the classroom. Podmore (1993) emphasized the role of quality assurance which requires governments to ensure that support, education, legislation, and supervision meet the society's expectations that early childhood experiences will benefit the children.

The KKK Mo extension program, in collaboration with Buddhist Compassion Relief Tzu Chi Foundation, supported the DCWs, parents, children, and barangay officials who brought impact to the day care centers. As shared by the various stakeholders in the barangay, the KKK Mo extension program provided varied activities for the DCWs, children, and parents. These activities brought a change in how the DCWs managed the DCCs, teach children, collaborate with the parents and community.

\section{Emerging Themes}

Following the thematic analysis of Colaizzi (1978), 34 significant statements were extracted from the beneficiaries' responses and were then capsulized into seven themes.

\section{Theme 1: Eliciting parents and children's active involvement}

Parental inclusion is a mix of duty and active interest concerning the parent to the school and the student (LaBahn, 1995). Parents are open to provide the necessary assistance to address the needs of the day care center. They readily assist in extending help in cooking and any other activities to support the plans of the DCCs. As one of the parents said "We volunteered to prepare the foods for the feeding program sponsored by the Department of Social Welfare and Development. We do marketing, cooking, and liquidating the allocated budget. This 
our way to support the day care workers. We are very happy about this opportunity because this is already a very big help to our children (P9). These parents' remarks were validated by the day care workers who emphasized that "We are very grateful of the help extended by the parents not only in the feeding program but also in other activities conducted for the DCCs. For instance, there was a gathering of day care children in the whole municipality and the parents accompanied their children. Their presence helped us a lot in ensuring the safety of the children (P13)". Vandergrift \& Greene as cited in LaBahn (1995) said that the blend of the degree of responsibility and compelling interest is the thing that makes an involved parent. Furthermore, the children become more confident and more involved in the day care center's activities. Dixon as cited in LaBahn (1995) mentioned that parental involvement, in any figure, produces quantifiable increases in student accomplishment.

Theme 2: Improving Collaboration and Communication

Communication between parents and educators established a cooperative relationship. It improved the whole child, not only educationally but socially and emotionally as well (McCarthy et al., 2011). The day care workers revealed that parents communicate more than before. As the day care workers revealed that "Parents are now more actively involved in the education of their children. During meetings, they readily gave suggestions and recommendations when we plan for activities (P13, P14, P15)". Also, both the DCWs and parents said that the activities initiated by the KKK Mo extension program and the Tzu Chi Foundation improved their collaboration and communication. As one volunteer from Tzu Chi Foundation commented: "I observed that parents are more participative than before. I am happy that they are participating in group activities, programs, and seminars initiated by KKK Mo (P19)". This observation was supported by one barangay official who said, "We have difficulty gathering the parents for meetings. But when this extension program began, I noticed that parents responded positively to their activities. I am amazed at the performance of parents during programs and activities. They participated well (P16)".

\section{Theme 3: Learning from Seminars}

The KKK Mo program prepared seminars for parents. The seminars were contextualized according to their needs and requests. The parents expressed the learning they gained from the seminars. They said that the seminars provided lessons on how to train their children to practice manners and right conduct. The resource speakers explained the topics well that enlighten them about parenting using positive discipline. As one mother said "I learned to understand my children. I have three boys whose ages are too close to each other. I easily got angry when they are disagreeing on something. Now that I am listening to the seminar on parenting, I realized that there are ways to discipline my children positively. Yes, it seemed hard to do but I will try (P10)." Giting et al. as cited in Somayeh et al. (2013) revealed in their study that positive programs for parents increase the responsibility. For the parents, the seminars taught them how positive discipline works and how to teach and guide their children properly. As one father mentioned: "I am ashamed to join this seminar. But when I heard about the topic, I was motivated to attend. I am thankful that as early as now I can correct my mistakes in disciplining my children. Hitting them once they commit mistakes is not good. Rather, having a dialogue with them is a better way to understand their side (P6)." 
The KKK Mo proponents used approaches in teaching values. The parents and volunteers from the Tzu Chi Foundation mentioned that KKK Mo initiated enjoyable and value-laden activities for the day care children. As Biktagirovaa and Valeevaa (2016) concluded that the family formed the values of the child. Participants $(2,4)$ stressed that "Parents need to teach the child about values and how to behave properly. We also attended seminars on how to discipline our children. They helped a lot about how we will raise our children."

\section{Theme 4: Availing necessities and learning resources}

The help extended to the day care centers benefited the children and their families. As the participants mentioned that "We are very grateful to the proponents of KKKMo and Tzu Chi Foundation. They provided some basic goods that helped a lot our family. It is not only the day care center that benefits their help but also our families. There is a big difference now in how the center looked than before. There are more learning materials that the children can use compared to before (P2). The rooms are more organized than before because they gave supplies, materials, and bookshelves (P14)." The beneficiaries reported that the KKK Mo extensionists and the Tzu Chi Foundation provided subsidies in the form of school supplies, rice, bookshelves, foods in the feeding program, vitamins, books, and materials used in structuring the day care classroom. The subsidy services encouraged involvement in the labor force to facilitate better child outcomes (Lowe \& Weisner, 2004). Since subsidies for child care and early education are an essential part of public efforts to help low-income families sustain themselves through jobs rather than welfare, this forms an integral part of improving children's experiences for low-income families. As one of the day care workers shared, "Before, I just tell stories without using any visual aid. But now, I can use big books that were donated by the KKKMo extensionists. Our room is more presentable. There are a lot of materials that I use in teaching. Children enjoyed the nursery rhymes that they shared with me (P13)".

\section{Theme 5: Increase in enrollment}

The enrollment increased since the KKK Mo extension program helped the DCCs. As the day care workers reported, "Before the KKK Mo and Tzu Chi Foundation came, many of our children transferred to the nearby barangays. But now, we have more children enrolled when they heard about KKK Mo and Tzu Chi Foundation (P13, P14, P15)". Parents also mentioned that "Some parents enrolled their children in the day care centers because they know that there are sessions about values education and other activities initiated by the extensionists and the Foundation (P1, P4, P19)". Both the parents and day care workers reported that there are more enrollees than before. They stressed that the day care centers have more enrollees compared to the nearby barangays. The transfer of children from other centers attributed to the increase in enrolment. The parents are more interested if KKK Mo and the Tzu Chi Foundation are around. Talbert (2012) stated that students develop feelings about their peers, educators, and institutions that give them a sense of connection, association, and belonging, thus, offering productive learning and development opportunities. The extension program is a contributing factor in the increase in enrollment in the DCCs.

Theme 6: Improving pedagogical competence and practices of day care workers

Being newly assigned in the center, the workers experienced difficulties managing the 
children and the learning environment. As one of the day care workers mentioned "When I was new in the center, I asked help from my partner DCW whose experience is more than 25 years. I observed her class and sought assistance on how to run my class. I availed of more help when KKK Mo adopted us. They provided seminars about some teaching strategies. I observed when they interact with the children (P13)." New teachers encountered problems in the classroom (Griffin et al. as cited in Costillas et al., 2016), which were also experienced by the day care workers. Thus, the preschool centers in a State University accommodated the DCWs. They observed the conduct of activities in teaching. Their exposure allowed them to benchmark on the best practices in teaching preschoolers. They reported what they learned from the benchmarking activities. The DCWs said, "It was my first time to observe a real classroom setting on how to teach preschoolers. I am amazed at how the children responded to the activities. I learn also ways on how to handle inattentive children. The teachers are great. They are very patient (P13). I learned some teaching strategies in my one-day observation in the preschool. It helped me a lot (P15)." Best practices are the adoption of established, discussed, and adopted good practices (Jarrar \& Zairi, 2000). The benchmarking activity helped the day care workers identify, learn from, and apply best practices in the day care center that make them more engaged in their work. Irudayaraj (2019) mentioned that more engaged employees are more committed and have focus and energy while at work. Further, providing training and mentoring programs to the DCWs helped them manage the center effectively and efficiently. Whitebook (1999) said that mentoring enhances mastery, how to innovate ways to improve. Mentoring is also a realistic and encouraging way for new caregivers to understand and resolve the challenges of the crucial first years at work. The day care workers' efficiency in running the DCCs was enhanced by the mentoring activities provided by the extensionists.

\section{Theme 7: Improving the learning environment}

In the management of the day care centers, the DCWs expressed the challenges they experienced. Both the parents and day care workers noticed that the classroom was very dull before the KKK Mo extension program. In a conversation with the day care workers, they expressed that "We are dependenton the donations for classroom structuring and acquisitions of learning materials. We had very minimal monthly honorarium. It is very difficult to purchase learning materials from our meager income (P13, P15)." Thus, the KKK Mo extensionists and the Tzu Chi Foundation coordinated with the barangay officials to rehabilitate the day care centers. The Tzu Chi Foundation provided the materials for classroom structuring, repainting, and renovating the classroom. A new TV was purchased. The difference in the appearance of the classroom at present was very noticeable to the parents, barangay officials, and community.

\subsection{Conclusion and Recommendations}

The KKK Mo extension program helped the day care workers establish sustainable and effective day care centers in collaboration with the local government unit. The KKK Mo extension program helped both the community and the University through forging and sustaining strong partnerships with government and non-government organizations. To ensure the sustainability of the KKK Mo extension project, it is recommended that day care workers be assisted to enroll in the Expanded Tertiary Education Accreditation Program (ETEAP) to earn 
a Bachelor's Degree. This could be done through a Memorandum of Agreement between the Department of Education and the Department of Social Welfare and Development. The DCW after passing the Licensure Examination for Teachers remains in the DCC with salary grade 11 as basic salary.

\section{Acknowledgment}

The proponents of the KKK Mo extension program are grateful to the Buddhist Compassion Relief Tzu Chi Foundation for sponsoring this project. The total project cost for 11 sessions was three hundred twenty-five thousand nine hundred fifty pesos (P325,950.00) for the meals, supplies, and training materials. The University's investment through the personnel services of seven faculty members who conducted the project and implemented its activities was thirty-two thousand pesos (P32,000.00). With the net amount of two hundred ninety-three thousand and nine hundred fifty pesos (P293,950.00), the University was able to save from the said partnership.

\section{References}

Abulon, E. L. (2013). Barangay day care center: Emergence, Current status and implications to Teacher Education. The Normal Lights Journal on Teacher Education, 5(1). http:// pnuresearchportal.org/ejournal/index.php/ normallights/article/view/57

Bastiaanssen, I. L., Kroes, G., Nijhof, K. S., Delsing, M. J., Engels, R. C., \& Veerman, J. W. (2012). Measuring group care worker interventions in residential youth care. Child \& Youth Care Forum, 41(5), 447-460. https://doi. org/10.1007/s10566-012-9176-8
Cadosales, M. N. Q. (2011). Enhancement activities for the day care centers and development workers. JPAIR Multidisciplinary Research Journal, 6(1). Retrieved from http://ejournals. ph/form/cite.php?id=7482

Colaizzi, P. F. (1978). Psychological research as the phenomenologist views it. In R. Valle \& M.

King (Eds.), Existential phenomenological alternative for psychology.

Costillas, J. M., Obus, M. E. \& Vitor, F. E. (2016). Screening Indicators for an Improved Faculty Accomplishment. Recoletos Multidisciplinary Research Journal, 4(1), 85-104. https://doi. org/10.32871/rmrj1604.01.10

Del Rosario, K., include all authors. (2018). Workrelated factors as determinants of selfefficacy and resilience among selected Filipino child development workers. IAFOR Journal of Education 6(3). https://files.eric. ed.gov/fulltext/EJ1198684.pdf.

Department of Social Welfare and Development. (2011). Administrative Order no. 15, s. 2011. https://www.dswd.gov.ph/issuances/AOs/ AO_2011-015.pdf no in-text citation found

Escarlos, G. S., Bermillo, J. E., Magday, E. R. J., \& Salon, V. S. (2019). An impact study on mentoring barangay day care workers extension program of the College of Education. International Journal of Scientific and Technology Research, 8(11). http://www.ijstr.org/paper-references. php?ref=IJSTR-0919-22334

Fuqua, R. W., \& Greenman, J. T. (1982). Training of caregivers and change in 
daycare center environments. Child Care Quarterly, 11(4), 321-324. https://doi. org/10.1080/10901020600675117

Garcia, L.E. \& Thornton, O. (2014). The enduring importance of parental involvement. http:// Neatoday.org/20 14/11/18/the- enduringimportance of parental-involvement-2/ .

Gulnara, B., \& Valeevaa, R. A. (2016). Study of family values of adolescents from families with many children formation. IEJME - Mathematics Education, 11 (6), 1919-1926. https://www. iejme.com/article/study-of-family-valuesof-adolescents-from-families-with-manychildren-formation

Harries, E., Hodgson, L., \& Noble, J. (2014). Creating your theory of change. https://www.thinknpc. org/wp-content/uploads/2018/07/Creatingyour-theory-of-change1.pdf

Irudayaraj, A. R. (2019). Teachers' Well-Being Through Work Engagement among Montfortian Schools in Asia. Recoletos Multidisciplinary Research Journal, 7(2), 61-78. https://doi.org/10.32871/rmrj1907.02.05

Jarrar, Y. F., \& Zairi, M. (2000). Best practice transfer for future competitiveness: a study of best practices. Total Quality Management, 11(4-6), 734-740. https://doi. org/10.1080/09544120050008147

LaBahn, J. (1995). Education and parental involvement in secondary schools: Problems, solutions, and effects. Educational Psychology Interactive. http://www.edpsycinteractive/ files/parinvol.html
Lau, E. YH, Li, H. \& Rao, H. (2011). Parental involvement and children's readiness for school in China. Educational Research, 53(1): 95-113. https://doi.org/10.1080/00131881.20 11.552243

Løvgren, M. (2016). Emotional exhaustion in daycare workers. European Early Childhood Education Research Journal, 24(1), 157-167. https://doi. org/10.1080/1350293X.2015.1120525

Lowe, E. D., \& Weisner, T. S. (2004). 'You have to push it-who's gonna raise your kids?': Situating child care and child care subsidy use in the daily routines of lower-income families. Children and youth services review, 26(2), 143-171. https://doi.org/10.1016/j. childyouth.2004.01.011

McCarthy, P. J., Brennan, L., \& Vecchiarello, K. (2011). Parent - school communication in the inclusive classroom: A comprehensive model of collaboration in education. International Journal of Humanities and Social Science, 1 (15), 55. http://www.ijhssnet.com/journals/Vol_1_ No_15_Special_Issue_October_2011/7.pdf

Ntekane, A. (2018). Parental involvement in education.DOI: 10.13140/RG.2.2.36330.21440

Peisner-Feinberg E.S. (2007). Child care and its impact on young children's development. In: Tremblay RE, Boivin M, Peters RDeV, eds. Bennett J, topic ed. Encyclopedia on Early Childhood Development [online]. http://www. child-encyclopedia.com/child-care-earlychildhood-education-and-care/accordingexperts/child-care-and-its-impact-young-1. 
Philippines. (2000). Republic Act No. 8980: Promulgating a comprehensive policy and system for Early Childhood Care and Development (ECCD). Quezon City, Philippines, Republic of the Philipines.

Pines, A., \& Maslach, C. (1980). Combatting staff burn-out in a daycare center: A case study. Child care quarterly, 9(1), 5-16. https://doi. org/10.1007/BF01555032

Podmore, V. N., Ed. (1993). What is the government's role in early childhood education? [Conference Presentation]. New Zealand Council for Educational Research Invitational Seminar. https://eric.ed.gov/?id=ED362265

Scriven, G. H., \& Baldridge, J. E. (1982). An in-service program to train daycare workers. Early Child Development and Care, 8(1), 69-77. https:// doi.org/10.1080/0300443820080107

Serrat, O. (2017). Theories of change. 10.1007/978981-10-0983-9_24

Somayeh, G., SayyedMirshah, J., SayyedMostafa, S., \& Azizollah, A. (2013). Investigating the effect of positive discipline on the learning process and its active strategies by focusing on the students' abilities. International Journal of Academic Research in Business and Social Sciences, 3 (5). 10.13140/2.1.3008.5128

Talbert, P. Y. (2012). Strategies to Increase Enrollment, Retention, and Graduation Rates. Journal of Developmental Education, 36(1), 22. https://www.semanticscholar.org/paper/ Strategies to Increase Enrollment, Retention, and Graduation Rates | Semantic Scholar
United Nations Educational Scientific and Cultural Organization. (2015). UNESCO and sustainable development goals. https://en.unesco.org/ sustainabledevelopmentgoals

Whitebook, M. (1999). Child care workers: High demand, low wages. The ANNALS of the American Academy of Political and Social Science, 563(1), 146-161. https://doi. org/10.1177/000271629956300109

Woolfolk, A. (2016). Educational psychology 13th Ed. Boston: Pearson. 